\title{
Perceived Versus Used Workplace Flexibility in Singapore: Predicting Work-Family Fit
}

\author{
Blake L. Jones \\ Brigham Young University - Provo \\ D. Phillip Scoville \\ Brigham Young University - Provo \\ E. Jeffrey Hill \\ Brigham Young University - Provo, jeff_hill@byu.edu \\ Geniel Childs \\ Brigham Young University - Provo \\ Joan M. Leishman

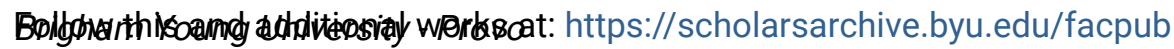 \\ Part of the Other Social and Behavioral Sciences Commons
}

See next page for additional authors

Original Publication Citation

Jones, B.L., Scoville, D.P., Hill, E.J., Childs, G., Leishman, J.M., \& Nally, K.S. (2008). Perceived versus used workplace flexibility in Singapore: Predicting work-family fit. Journal of Family Psychology, 22(5), 774-783.

\section{BYU ScholarsArchive Citation}

Jones, Blake L.; Scoville, D. Phillip; Hill, E. Jeffrey; Childs, Geniel; Leishman, Joan M.; and Nally, Kathryn S., "Perceived Versus Used Workplace Flexibility in Singapore: Predicting Work-Family Fit" (2008). Faculty Publications. 4044.

https://scholarsarchive.byu.edu/facpub/4044

This Peer-Reviewed Article is brought to you for free and open access by BYU ScholarsArchive. It has been accepted for inclusion in Faculty Publications by an authorized administrator of BYU ScholarsArchive. For more information, please contact ellen_amatangelo@byu.edu. 
Authors

Blake L. Jones, D. Phillip Scoville, E. Jeffrey Hill, Geniel Childs, Joan M. Leishman, and Kathryn S. Nally 


\title{
Perceived Versus Used Workplace Flexibility in Singapore: Predicting Work-Family Fit
}

\author{
Blake L. Jones, D. Phillip Scoville, E. Jeffrey Hill, Geniel Childs, Joan M. Leishman, \\ and Kathryn S. Nally \\ Brigham Young University
}

\begin{abstract}
This study examined the relationship of 2 types of workplace flexibility to work-family fit and work, personal, and marriage-family outcomes using data $(N=1,601)$ representative of employed persons in Singapore. We hypothesized that perceived and used workplace flexibility would be positively related to the study variables. Results derived from structural equation modeling revealed that perceived flexibility predicted work-family fit; however, used flexibility did not. Work-family fit related positively to each work, personal, and marriage-family outcome; however, workplace flexibility only predicted work and personal outcomes. Findings suggest work-family fit may be an important facilitating factor in the interface between work and family life, relating directly to marital satisfaction and satisfaction in other family relationships. Implications of these findings are discussed.
\end{abstract}

Keywords: job satisfaction, marital satisfaction, perceived workplace flexibility, used workplace flexibility, work-family fit

Over the past several decades, researchers, businesses, and funding agencies have devoted significant time and money to studying the interface between work and family life. The ability to balance the demands of work and family life is related to valued work, family, and personal outcomes (Sandholtz, Derr, Buckner, \& Carlson, 2002). Achieving balance between work and family life has become harder for many individuals because work hours and job demands have increased for many nations around the world. As Sandholtz et al. noted, some changes in work environments and job expectations are related to negative outcomes in employee performance and work satisfaction (Reynolds \& Aletraris, 2007), family life (Stevens, Kiger, \& Riley, 2006), and personal life (Costa, Sartori, \& Akerstedt, 2006). In this article, we focused on the connection between workplace flexibility and work-family fit. We developed a conceptual model to examine the influence that perceived and used workplace flexibility had on work-family fit, and how workplace flexibility and work-family fit related to specific work, personal, and marriage-family outcomes. This study contributes to work and family research by using a popula-

Blake L. Jones, D. Phillip Scoville, E. Jeffrey Hill, Geniel Childs, Joan M. Leishman, and Kathryn S. Nally, School of Family Life, Brigham Young University.

Funding for this study came from a partnership between the Family Studies Center at Brigham Young University, Provo, Utah and the Ministry of Community Development, Youth and Sports, Republic of Singapore.

Correspondence concerning this article should be addressed to Blake L. Jones, 2086 JFSB, Brigham Young University, Provo, UT 84602. E-mail:blakejones13@gmail.com tion from Singapore, where little work and family research has been conducted.

\section{Rationale for Using a Sample From Singapore}

The preponderance of past research on the intersection of work and family life has been conducted in the United States. The workplace environment in Singapore has been associated with unique factors that could relate to potential differences in the balance between work and family life. For example, in Singapore the percentage of dual earners in a family has doubled since 1980, and the average number of hours worked per week in Singapore is 48, with men averaging $51 \mathrm{hr} /$ week and women averaging $46 \mathrm{hr} /$ week (Hill, 2007). Working conditions in Singapore appear to be more rigid than in the United States and most other developed nations. Although both the United States and Singapore have reported long work weeks and high numbers of dual earner families, Singapore reported much less access to flexible work options. Although 38\% of Americans reported having considerable, or complete flexibility in when they work, only 13\% of workers in Singapore reported this level of flexibility. Singaporean workers who had flexible options were also much less likely to use them (Hill, 2007). Working longer hours, coupled with having less workplace flexibility, has been associated with negative work, personal, and marriage-family outcomes (Hill, Hawkins, Ferris, \& Weitzman, 2001).

The interface between work and family life is important worldwide. Recent studies have been conducted in Hong Kong (Aryee, Luk, \& Stone, 1998), India (Larson, Verma, \& Dworkin, 2001), the United Kingdom (Thornthwaite, 2004), Canada (Frone \& Yardley, 1996), Australia (Reynolds \& Aletraris, 2007), and The Netherlands (Van den Berg 
\& Van der Velde, 2005). Singapore represents an important and unique population for work and family research because it is a nation where little of this kind of research has been undertaken. Also, because Singapore's working conditions seem to be somewhat rigid and demanding, this study offers a potentially unique contribution to the current work and family literature.

\section{Work-Family Conflict, Work-Family Fit, and Spillover Theory}

Past research on work and family has generally focused on the negative impact of work on the individual and the family. Such research has often focused on the concept of work-family conflict (Netemeyer, Boles, \& McMurrian, 1996). Work-family conflict theories suggest that experiences in work roles can result in diminished performance in other roles, such as family roles (Greenhaus, Allen, \& Spector, 2006). For example, the amount one works impacts one's ability to care for family and self. This theory is derived from a scarcity hypothesis that assumes that individuals who have multiple roles will inevitably experience conflict and stress that may detract from their quality of life (Greenhaus \& Powell, 2006). Work-family conflict is an even bigger issue for individuals who have limited resources to meet the demands they face. Stevens et al. (2006) found that stress caused by work and family imbalance was associated with lower marital satisfaction, less time spent with a partner or children, and having fewer children in general. When work or family demands exceed resources, strain or conflict is experienced (Voydanoff, 2005). For this reason, some work and family research has focused on the compounding effects from role strain that seem to be related to work-family conflict. For example, Morris and Coley (2004) found that long work hours and work transitions related to higher maternal role strain for lowincome mothers.

Although much emphasis has been placed on the conflict that arises from work and family interactions, there are more salutogenic concepts that have emerged that focus on the benefits between work and family, as opposed to the conflict (Grzywacz \& Bass, 2003). These concepts have been called a number of different terms, including work-family balance (Clark, 2000) and work-family fit (Pittman, 1994; Voydanoff, 2005). In this study, we have chosen to use workfamily fit. Work-family fit can be described as the ability to integrate work and personal/family life in a successful manner (Hill et al., 2008). Work-family fit is distinct from an absence of conflict (Grzywacz \& Bass, 2003). The concept of work-family fit involves a cognitive appraisal of the effects that work, personal, and family domains have on each other. Fit occurs when resources are available to meet demands in each domain. Clearly, work and family life resources and demands can interact or spill over into other domains in positive or negative ways. In conjunction with work-family fit, the conceptual model in this study draws from the spillover theory to postulate the effects that perceived workplace flexibility and used workplace flexibility have on work-family fit (Bromet, Dew, \& Parkinson, 1990).
The spillover theory suggests that there can be positive or negative spillover from the work environment or the family environment to one another (Hill, Ferris, \& Martinson, 2003). The benefit of work on personal and family life is caused by many different factors within the work environment, including additive effects of role accumulation and the buffering effect of one role on another (Greenhaus \& Powell, 2006).

\section{Workplace Flexibility}

Flexibility has become a catchword for employers (Sanchez, Perez, de Luis Carnicer, \& Jimenez, 2007) and families (Keene \& Reynolds, 2005), and seems to relate to work, personal, and marriage-family outcomes (Clarke, Koch, \& Hill, 2004; Grzywacz \& Bass, 2003). Flexibility has been associated with commitment and productivity at work (Golden, Veiga, \& Simsek, 2006), lower levels of work-family conflict (Grzywacz, Almeida, \& McDonald, 2002), lower levels of physical and mental health problems (Kossek, Lautsch, \& Eaton, 2006), and having a sense of personal agency and creativity (Galinsky, Bond, \& Hill, 2004). Interest in flexibility in paid work has grown considerably in the past decade. The U.S. Department of Labor (1999) reported that flexibility and family is a significant challenge currently facing workers and employers. When examining workplace flexibility, it is important to understand that it can be seen from either an organizational or a worker's perspective. This study examines flexibility from a worker's perspective. Workplace flexibility is defined as "the ability of workers to make choices that influence when, where, and for how long they engage in work-related tasks" (Hill et al., 2008, p. 152). As workplace flexibility research has grown, support for this as a beneficial option for both employers and employees has continued to gain momentum (Hill et al., 2008). Workers have flocked to workplace flexibility as a way to meet family needs in today's demanding work environment. Businesses have adopted such strategies because they have seen the value in increasing worker performance and annual revenues (Sandholtz et al., 2002).

\section{Perceived Versus Used Workplace Flexibility}

Even when employers make flexible workplace options available, there is a distinction between having flexibility and using flexibility. Kossek et al. (2006) pointed out that the influence of used workplace flexibility on workplace, personal, and marriage-family outcomes can differ from the influence of perceived flexibility on those same variables. Using flexible options can be beneficial; however, research has shown that many workers benefit from workplace flexibility without actually using many of the specific options available. Simply perceiving that flexible options were available when needed seems to be related to positive outcomes (Frone \& Yardley, 1996; Hill, Miller, Weiner, \& Colihan, 1998). Employees with greater perceived flexibility reported significantly lower work-family conflict, depression, and job turnover intentions (Kossek et al., 2006). In a study conducted on IBM employees, researchers 
found that those with more perceived flexibility reported more work-family balance, and were able to work 8 more hours per week before reporting work-family conflict, when compared to workers with less perceived flexibility (Hill et al., 2001). A lack of available workplace flexibility is significant because flexibility in when and where work is done can mediate the relationship between long work hours and negative outcomes (Hill, 2007). Thus, employees who perceive that they have more control over workplace characteristics may then perceive more fit between workplace, family, and their personal lives. For example, Hill et al. (2001) found that those who perceived more flexibility at work had greater work-family fit.

\section{Workplace Outcomes}

Job satisfaction and job engagement were included as workplace outcomes in the conceptual model. Grandey, Cordeiro, and Crouter (2005) defined job satisfaction as a cognitive evaluation of a job experienced as favorable or unfavorable. Multiple studies have shown that workplace flexibility is related to greater job satisfaction (Baltes, Briggs, Huff, Wright, \& Neuman, 1999; Pierce \& Newstrom, 1983). In addition, research by Macan (1994) found a positive relationship for employees between perceived control of time (one aspect of job flexibility) and job satisfaction. Job engagement is closely tied to job satisfaction. Organizations who offer flexible work options reported higher levels of engagement from their employees (Wang \& Walumbwa, 2007). One explanation for this is that employees who have greater flexibility to balance work, personal, and family demands will have more favorable attitudes toward work and greater attachment to their company, leading to greater job engagement (Allen, 2001; Pierce \& Newstrom, 1983).

\section{Personal Outcomes}

Physical health and mental health were included as personal outcomes in the conceptual model. Multiple studies have noted relationships between workplace flexibility and an individual's health as well as one's mental health and stress levels (Grzywacz, Carlson, \& Shulkin, 2008). Pierce and Newstrom (1983) found that flexible working hour arrangements decreased symptoms of stress. Costa et al. (2006) found that workplace flexibility influenced important personal outcomes, such as lower rates of stress, fatigue, irritability, headache, stomachache, anxiety, and injury. Important personal outcomes, such as physical health and mental health, might be influenced by workplace flexibility, which may then spill over into other areas of one's life, such as work, marriage, and family.

\section{Marriage and Family Outcomes}

Marital satisfaction, family satisfaction, family relationships satisfaction, and child relationship satisfaction were included as marriage-family outcomes in the conceptual model. Workplace demands influence family relationships and family out- comes (Reynolds \& Aletraris, 2007). For example, an association has been found between employees who work evening shifts and negative effects within the home environment, such as an increase in divorce rates (Perry-Jenkins, Repetti, \& Crouter, 2001). The home environment has been shown to affect children's academic achievement as well as other areas of their development and their health outcomes (Heymann \& Earle, 2001). Frustrations related to work environments have been connected to more anger in marital behaviors and decreased marital satisfaction (Schultz, Cowan, Cowan, \& Brennan, 2004). Job stressors in the workplace have also been associated with negative parenting outcomes (Repetti \& Wood, 1997). Meanwhile, workplace flexibility has been found to have a positive influence on family life (Hill et al., 1998; Keene \& Reynolds, 2005). One explanation may be that greater workplace flexibility is able to reduce role strain and have a positive spillover into marriage and family life (Morris \& Coley, 2004).

\section{Hypotheses}

The work-family conflict model, as well as the spillover theory, state that work characteristics impact personal and family outcomes. Research has shown connections between work-family fit, workplace flexibility, and some work, personal, and family outcomes (Brennan, Rosenzweig, Ogilvie, Wuest, \& Shindo, 2007; Clarke et al., 2004). Workplace flexibility may influence the interface between work and family, lowering work-family conflict and improving work-family fit for workers in Singapore. Especially given the demanding work environment in Singapore, we anticipated that workplace flexibility would be related to positive spillover. For these reasons, we made the following hypotheses:

H1. That greater perceived workplace flexibility would be related to improved work-family fit.

H2. That greater used workplace flexibility would be related to improved work-family fit.

H3. That greater work-family fit would be positively related to work, personal, and marriage-family outcomes.

H4. That perceived and used workplace flexibility would be positively related to workplace, personal, and marriage-family outcomes.

\section{Method}

\section{Sample}

The sample consisted of 1,601 employed persons in Singapore (840 men, 52.5\%, 761 women, 47.5\%). Respondents were chosen to be a nationally representative of workers in Singapore in terms of gender, age, race, and house type (a proxy for socio-economic status [SES]) based on information from the Department of Statistics (as cited in Hill, 2007). The mean age for the sample was 38.10 years $(S D=10.81)$. Approximately two-thirds of the respondents were married: first marriage (64\%); single, never married (31\%); divorced 
(3\%); widowed (1\%); remarried (1\%); and separated (1\%). Of the workers that had children, the average number of children was two or less (43\% had no children, $18 \%$ had one child, $27 \%$ had two children, $10 \%$ had three children, and $3 \%$ had between four and six children). The mean individual income was approximately $\$ 2,300$ per month, and the mean household income was $\$ 4,200$ per month. The sample was diverse in education: $48 \%$ had completed high school or less and $52 \%$ had attended some college or technical school or above. Religious orientation was also diverse: Buddhist (38\%), Muslim (22\%), Christian (16\%), no religion (13\%), and other (12\%); as well as the ethnicity: Chinese (70\%), Malay (20\%), Indian $(9 \%)$, and other $(1 \%)$.

\section{Procedure}

Before data collection began, focus groups, consisting of 93 employed workers in Singapore, were used to develop appropriate questionnaire items and test the validity of the conceptual model. A pilot study was conducted with 435 employed workers in Singapore. The original 223 questions took participants 60 to $90 \mathrm{~min}$ to complete. Because the desired time of completion for the survey was 30 to $45 \mathrm{~min}$, factor analyses were conducted to eliminate redundant questions and make the survey more parsimonious. The surveys were administered by an independent company, as a onetime interview. During the questionnaire, each item was read aloud to participants by the interviewers.

\section{Measures}

The final survey consisted of 155 items, which were designed to explore family life, and how work environments and flexibility affected workplace, personal, and marriagefamily outcomes. The main variables used in the analyses of this study included work-family fit, perceived workplace flexibility, and used workplace flexibility. Other specific outcome variables from work-family fit were linked with one of three outcome areas: work outcomes (job satisfaction and job engagement), personal outcomes (physical health and mental health), and marriage-family outcomes (marital satisfaction, family satisfaction, family relationship satisfaction, and child relationship satisfaction).

Work-family fit was a scale composed of nine items that assessed how well people balanced work and family life. The first item measured the difficulty level of integrating work and personal/family life. The second item compared this level of difficulty integrating work and personal/family life to 3 years prior. The third item measured individual efficacy of integrating work responsibilities and personal/family aspirations. The final six items of the scale measured level of agreement or disagreement to the following individual statements (my job fits well with: my individual personality, my desire to be happily married, my desired number of children, my desire to spend time with my family and children, my preferred pace (tempo) of life, and my desire for social interaction). The scale yielded a Cronbach's alpha of .87. Perceived workplace flexibility, an exogenous variable, was composed of two items on a 4-point Likert scale. The questions were asked how much control (flexibility) the respondents had in scheduling WHEN they worked, and how much control (flexibility) they had in scheduling WHERE they worked. The scale had a Cronbach's alpha of .91. Used workplace flexibility, a second exogenous variable, was measured by three items. The questions asked participants how often they chose when they started and ended work within some range of hours, how often they arranged to work part-time ( $30 \mathrm{hr}$ per week or less) in their current position, and how often they arranged to work from home in their current position. This scale had a Cronbach's alpha of .58.

Job engagement was measured by a 4-point Likert scale item asking respondents how willing they were to work harder than they had to, to help their organization. Job satisfaction was measured by a 4-point Likert scale item asking respondents how satisfied they were with their job. Physical health was measured by a 4-point Likert scale item asking respondents how they rated their current state of health. Mental health was an index that was composed of seven items that asked individuals about how often they felt nervous, stressed, overwhelmed, unable to sleep, a loss of interest, a loss of control, or bothered by health problems associated with anxiety. The mental health scale yielded a Cronbach's alpha of .92. Marital satisfaction was an index of five items that asked participants about marital relationships (e.g., overall satisfaction, quality of marital communication). The marital satisfaction scale yielded a Cronbach's alpha of .94. Family satisfaction was measured by a 4-point Likert scale item asking respondents how satisfied they felt in their family life and home environment. Family relationship satisfaction was measured by a 4-point Likert scale item asking respondents how satisfied they were with their relationship(s) with their family. For married respondents with children, child relationship satisfaction was measured by a 4-point Likert scale item asking respondents how satisfied they were with their relationship(s) with their children.

\section{Analyses}

Demographic and descriptive statistics were examined to assess differences within the population. We then conducted a correlation analysis to assess the relationships among the variables in the conceptual model. A regression model was conducted to analyze the first and second hypotheses, examining the validity of perceived and used workplace flexibility as predictors of work-family fit. Structural equation modeling $(S E M)$ was used to model the relations among the latent variables of interest in this study to estimate the conceptual model (See Figure 1). Model fit, analyses of path coefficients, and other analyses for the model were examined using AMOS 7.0 (SPSS, 2007).

A model was estimated with respondents that had complete data $(n=1,590)$. Based on the significance of the standardized parameter estimates, the model was trimmed to exclude the paths that were nonsignificant at the $p<.05$ level (see Figure 2). The model produced goodness-of-fit indexesincluding chi-square, comparative fit index (CFI), TuckerLewis Index (TFI), and root mean square error of approximation (RMSEA). In following the recommendations of Hoyle and Panter (1995), we reported both absolute fit 


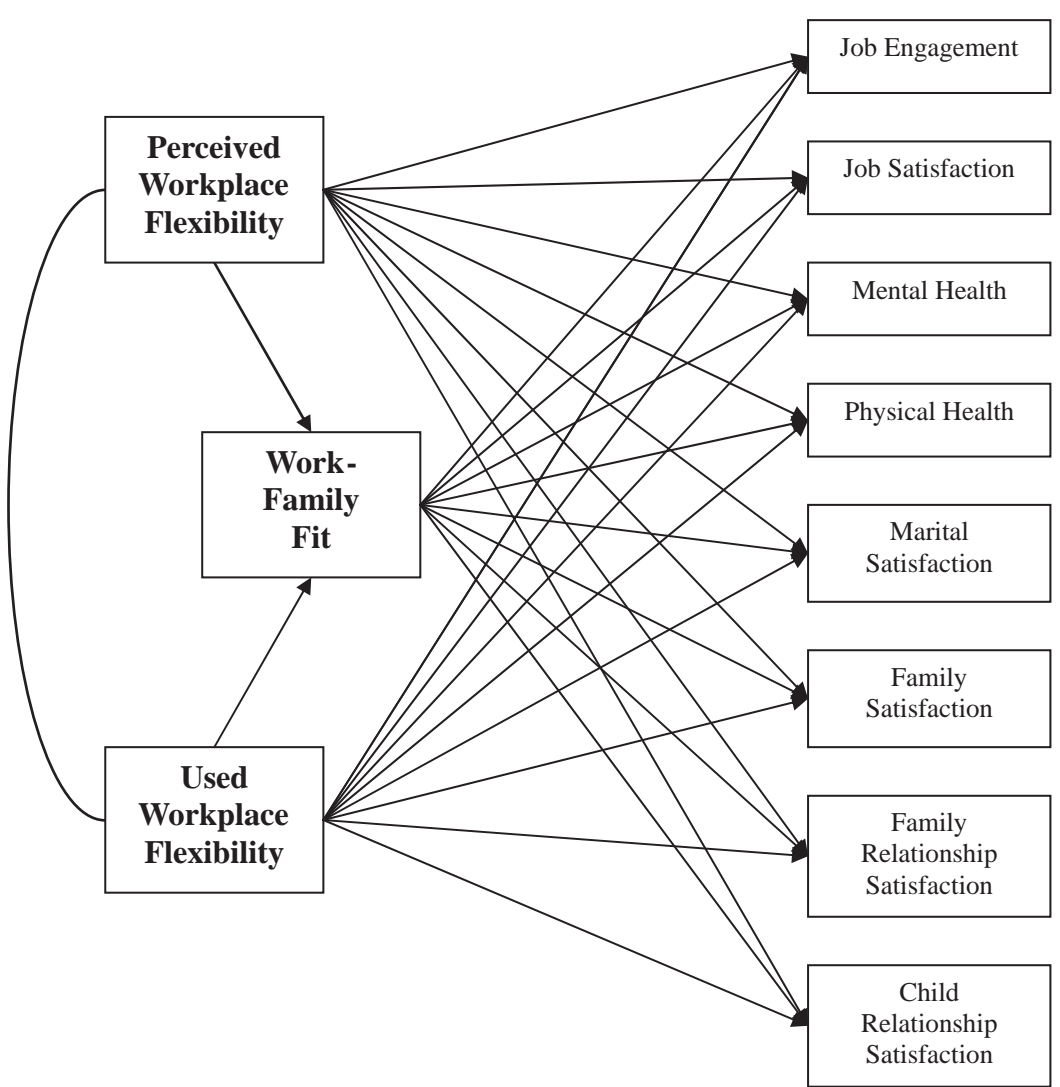

Figure 1. Initial conceptual model for workplace flexibility and work-family fit.

indexes and incremental fit indexes. Hoyle and Panter recommended using the chi-square statistic as a general index as well as two types of incremental fit indexes. Accordingly, we reviewed the model, and then reported on the Tucker and Lewis Index (TLI) as well as the CFI (Hoyle and Panter, 1995). Both of these indexes range from 0 to 1.00. TLI and CFI values close to, or above, .95 are representative of good fit (Byrne, 2001). The RMSEA is also reported, which is considered to be one of the most informative criteria in SEM (Byrne, 2001). A value below .05 is considered to indicate good fit (Arbuckle, 2006).

\section{Results}

Descriptive statistical analyses were conducted to address differences in variables by gender, age, marital status, and earner status. Men reported greater perceived workplace flexibility than females; however, females reported using more workplace flexibility than males. Workers over age 40 reported significantly higher perceived workplace flexibility, used workplace flexibility, and work-family fit than younger workers. Younger workers, under age 40, reported significantly higher physical health, family satisfaction, and parent-child relationship satisfaction. Married workers, especially dualincome families, reported more perceived workplace flexibility and used workplace flexibility. Single-earner families reported working more hours per week $(M=50.13, S D=11.38)$ than employees from dual-earner families who both worked fulltime $(M=46.53, \mathrm{SD}=11.60)$.

Correlational analyses were conducted to examine the relations between perceived workplace flexibility, used workplace flexibility, work-family fit, and the work, personal, and marriage-family outcomes (See Table 1). Work-family fit was significantly related with each of the work, personal, and marriage-family outcomes. All of these outcomes were significantly related to one another. In general, outcome variables were especially related to the other variables within their specific domain (work, personal, or marriage-family). Perceived and used workplace flexibility was significantly related to one another. Perceived workplace flexibility had higher correlations with work-family fit and the other outcomes than used flexibility did. However, both perceived and used workplace flexibility had only small or modest correlations with the outcome variables.

Multiple regression analyses were conducted to evaluate how well perceived workplace flexibility and used workplace flexibility predicted work-family fit. The overall regression analysis was significant, $R^{2}=.047, F(2,1598)=37.08, p<$ .001 . When the regression analysis was conducted separately by gender, it was significant for both men, $R^{2}=.044, F(2$, $837)=19.41, p<.001$, and women, $R^{2}=.047, F(2,758)=$ $18.87, p<.001$. The analyses of variances (ANOVAs), 


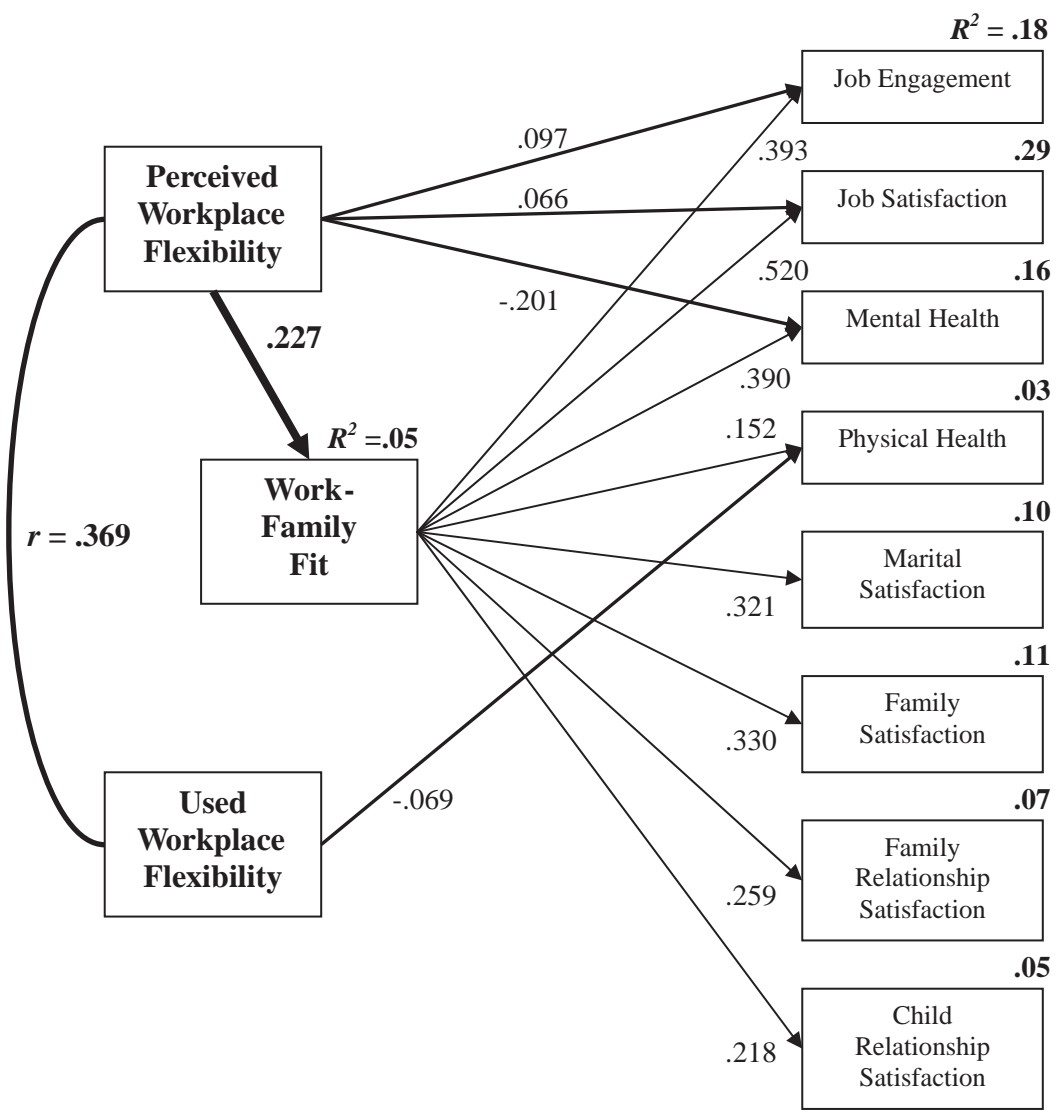

Figure 2. Final structural equation modeling (SEM) model for workplace flexibility, work-family fit, and other outcomes. All parameter estimates shown in the final, trimmed model are standardized to allow for comparisons across variables based on different scales. Only paths with significant estimates at the $p<.05$ level were kept in this trimmed model.

$R$-squared, and beta score results for men and women were very similar (see Table 2). Thus, this regression model seemed to predict work-family fit for men and women at about the same levels. The overall results of this analysis demonstrated that higher levels of work-family fit were predicted by higher levels of perceived workplace flexibility, but not used workplace flexibility, in both men and women.

\section{SEM Analyses and Results of Hypotheses}

After trimming out the nonsignificant paths in the model, the overall analysis showed that the model had a good fit to the data, $\chi^{2}(13, N=1590)=18.85, p=.128 ; \mathrm{CFI}=.998$; $\mathrm{TLI}=.992 ; \mathrm{RMSEA}=.017$ (see Figure 2$).$ The chi-square was low, and was not significant.

Table 1

Means and Intercorrelations for Variables in the Conceptual Model

\begin{tabular}{|c|c|c|c|c|c|c|c|c|c|c|c|c|c|}
\hline Variable & $M$ & $S D$ & 1 & 2 & 3 & 4 & 5 & 6 & 7 & 8 & 9 & 10 & 11 \\
\hline 1. Work-family fit & 2.81 & .40 & - & & & & & & & & & & \\
\hline 2. Job engagement & 3.04 & .50 & $.42^{* * *}$ & - & & & & & & & & & \\
\hline 3. Job satisfaction & 2.97 & .51 & $.54^{* * *}$ & $.59^{* * *}$ & - & & & & & & & & \\
\hline 4. Physical health & 2.91 & .49 & $.15^{* * *}$ & $.10^{* * * *}$ & $.14^{* * *}$ & - & & & & & & & \\
\hline 5. Mental health & 3.84 & .72 & $.35^{\text {*** }}$ & $.20^{* * *}$ & $.25^{* * *}$ & $.33^{* * *}$ & - & & & & & & \\
\hline 6. Marital satisfaction & 2.64 & .59 & $.32^{* * *}$ & $20^{* * *}$ & $.23^{* * *}$ & $.12^{* * *}$ & $.15^{* * *}$ & - & & & & & \\
\hline 7. Family satisfaction & 2.54 & .67 & $.33^{\text {*** }}$ & $23^{* * *}$ & $29^{* * *}$ & $.23^{\text {*** }}$ & $25^{* * *}$ & $.48^{* *}$ & - & & & & \\
\hline 8. Family relationship satisfaction & 2.72 & .58 & $.26^{* * *}$ & $.21^{* * * *}$ & $24^{* * *}$ & $.19^{* * * *}$ & $20^{* * *}$ & $.56^{* * *}$ & $.43^{* * *}$ & - & & & \\
\hline 9. Child relationship satisfaction & 2.87 & .58 & $.25^{* * *}$ & $.25^{* * *}$ & $.30^{* * *}$ & $.17^{* * *}$ & $.11^{\text {*** }}$ & $.51^{* *}$ & $.36^{* * *}$ & $.59^{* *}$ & — & & \\
\hline 10. Perceived flexibility & 1.65 & .78 & $.23^{\text {*** }}$ & $.19^{* * *}$ & $.19^{\text {*** }}$ & .03 & $-.11^{\text {*** }}$ & $.07^{*}$ & $.08^{* * *}$ & $.05^{*}$ & $.07^{*}$ & - & \\
\hline 11. Used flexibility & 1.25 & .43 & $.08^{* * *}$ & $.09^{* * *}$ & $.10^{* * *}$ & $-.07^{* * *}$ & $-.07^{* * *}$ & -.02 & .03 & .02 & -.01 & $.37^{* * *}$ & - \\
\hline
\end{tabular}

${ }^{*} p<.05 .{ }^{* * *} p<.01$. 
Table 2

Regression Results for Predictors of Work-Family Fit

\begin{tabular}{|c|c|c|c|c|c|c|}
\hline Predictors & & $B$ & $S E$ & $\beta$ & $t$ & $p$ \\
\hline \multirow[t]{3}{*}{ Total sample } & Constant & 2.627 & .032 & 81.217 & & $.000^{* * * * * *}$ \\
\hline & Perceived workplace flexibility & 0.119 & .014 & 0.230 & 8.739 & $.000^{* * * * \cdots}$ \\
\hline & Used workplace flexibility & -0.006 & .025 & -0.007 & -0.251 & .802 \\
\hline
\end{tabular}

Hypothesis 1 was supported in the model. Perceived workplace flexibility had a significant direct effect on workfamily fit (path coefficient $=.235 ; p<.01$; see Table 3 for decomposition of effects of the trimmed SEM model), and accounted for $5 \%$ of the overall variance in work-family fit. Hypothesis 2 was not supported because used workplace flexibility had a nonsignificant relationship with workfamily fit ( $p=.752$.). Hypothesis 3 was supported in the model. Work-family fit was positively related to each of the work, personal, and marriage-family outcomes (standardized path coefficients from work-family fit to the outcomes were as follows: to job engagement $=.393$, to job satisfaction $=$ .520 , to mental health $=.390$, to physical health $=.152$, to marital satisfaction $=.321$, to family satisfaction $=.330$, to family relationship satisfaction $=.259$, and to child relationship satisfaction $=.218$; see Table 3 and Figure 2). Hypothesis 4 was only partially supported. The model showed that perceived flexibility had significant path coefficients to job engagement, job satisfaction, and mental health, and that used flexibility had a significant path coefficient to physical health. Neither perceived nor used workplace flexibility had any significant path coefficients to any of the marriage-family outcomes (see Table 4).

\section{Discussion}

The most significant finding from this study is that, at least in Singapore, the perception of having flexibility in

Table 3

Decomposition of Effects From SEM of Workplace Flexibility and Work-Family Fit

\begin{tabular}{|c|c|c|c|}
\hline & Direct & Indirect & Total \\
\hline \multicolumn{4}{|l|}{ Effects on work-family fit } \\
\hline Perceived workplace flexibility & .227 & NA & .227 \\
\hline Used workplace flexibility & .000 & NA & .000 \\
\hline \multicolumn{4}{|l|}{ Effects on job engagement } \\
\hline Perceived workplace flexibility & .097 & .089 & .188 \\
\hline Used workplace flexibility & .000 & .000 & .000 \\
\hline Work-family fit & .393 & $N A$ & .393 \\
\hline \multicolumn{4}{|l|}{ Effects on job satisfaction } \\
\hline Perceived workplace flexibility & .066 & .118 & .185 \\
\hline Used workplace flexibility & .000 & .000 & .000 \\
\hline Work-family fit & .520 & $N A$ & .520 \\
\hline \multicolumn{4}{|l|}{ Effects on physical health } \\
\hline Perceived workplace flexibility & .000 & .035 & .035 \\
\hline Used workplace flexibility & -.069 & .000 & -.069 \\
\hline Work-family fit & .152 & $N A$ & .152 \\
\hline \multicolumn{4}{|l|}{ Effects on mental health } \\
\hline Perceived workplace flexibility & -.201 & .089 & -.112 \\
\hline Used workplace flexibility & .000 & .000 & .000 \\
\hline Work-family fit & .390 & $N A$ & .390 \\
\hline \multicolumn{4}{|l|}{ Effects on marital satisfaction } \\
\hline Perceived workplace flexibility & .000 & .073 & .073 \\
\hline Used workplace flexibility & .000 & .000 & .000 \\
\hline Work-family fit & .321 & $N A$ & .321 \\
\hline \multicolumn{4}{|l|}{ Effects on family satisfaction } \\
\hline Perceived workplace flexibility & .000 & .075 & .075 \\
\hline Used workplace flexibility & .000 & .000 & .000 \\
\hline Work-family fit & .330 & $N A$ & .330 \\
\hline \multicolumn{4}{|c|}{ Effects on family relationship satisfaction } \\
\hline Perceived workplace flexibility & .000 & .059 & .059 \\
\hline Used workplace flexibility & .000 & .000 & .000 \\
\hline Work-family fit & .259 & $N A$ & .259 \\
\hline \multicolumn{4}{|c|}{ Effects on child relationship satisfaction } \\
\hline Perceived workplace flexibility & .000 & .050 & .050 \\
\hline Used workplace flexibility & .000 & .000 & .000 \\
\hline Work-family fit & .218 & $N A$ & .218 \\
\hline
\end{tabular}

Note. $\quad S E M=$ structural equation modeling; $N A=$ not applicable. 
when and where one works is a more powerful predictor of work-family fit and desired outcomes than actually using that flexibility. This suggests that the adoption and publicizing of workplace flexibility programs may benefit all employees, not just those who are in a position to currently use the programs. For example, a company may implement a work-at-home program for professionals. Perhaps at present only $5 \%$ of the employees opt to use that program. These data suggest that adopting the program may lead the other $95 \%$ of the employees to improve their perception of how much workplace flexibility they enjoy. This enhanced perception of flexibility in when and where work is done may lead to greater work-family fit, which in turn may lead to improved job satisfaction and engagement, better mental and physical health, and enhanced marital, family, and child relationship satisfaction. It appears the adoption of flexible work options may benefit entire organizations, not just those who presently use those programs.

There are several potential explanations for why perceived workplace flexibility is significantly related to workfamily fit although used flexibility is not. It may be that workers who know they have flexible options available if needed are able to feel more balanced by having reduced stress and role strain between work demands and family life. For many parents and caregivers, the perception of workplace flexibility seems to be an important factor that empowers them and gives them a sense of increased agency. They may feel less trapped between work and family. Because of the higher perceived workplace flexibility, workers may feel like they have more control over other aspects of their lives as well. This increased feeling of control in when and where work is accomplished is likely to result in positive spillover that may improve reports of work-family fit.

A perplexing finding is that in these Singaporean data used workplace flexibility did not significantly relate to workfamily fit in the model. This finding is different than what has been found in other studies. One possible explanation may hinge on the fact that workplace flexibility in Singapore is not widely available, is used infrequently, and is not supported by the workplace culture. Mainstream employees may avoid using workplace flexibility programs because they fear such usage may be deleterious to their career. So there may be a selection effect because only those already experiencing significant role strain and stress already take the risk to actually use these programs. In addition, it may be the programs are helpful to those that use them, but they do not have better outcomes than those not using the programs. For instance, a worker may use telecommuting to better care for an aging grandparent at home. However, this worker's chronic care demands may lead to more stress and lower work-family fit than would be found by a typical worker not using a flexible work arrangement. A final explanation for this unexpected finding is that the scale comprising used workplace flexibility has relatively low reliability $(\alpha=.58)$. Thus, measurement error may account for the lack of significant results. Future research will likely benefit from developing a used workplace flexibility variable with higher scale reliability.

Results clearly showed that work-family fit was significantly related to each of the work, personal, and marriage- family outcomes. This finding supports other research that demonstrates that work-family fit is an important factor in the well-being of employees who are trying to manage multiple roles (e.g., Bromet et al., 1990; Hill et al., 2008). Work-family fit seems to effectively measure a worker's ability to balance demands overall between work, personal, and family life so that the outcomes of each area are positively related to higher levels of reported workfamily fit.

Another important finding is that the positive relationships between perceived workplace flexibility and family-related outcome variables are not direct, but indirect through work-family fit. This means that perceived workplace flexibility is positively related to outcomes of interest to family psychologists only to the degree that family members see this flexibility as a means to improve their cognitive perception of the fit between work and personal/family demands.

Finally, from a broad perspective, the results of this study from Singapore highlight the importance of family psychologists considering perceptions individuals have of their work environment as well as the interface between work and family life when trying to explain family outcomes.

It is unclear why perceived flexibility had a negative relationship with mental health. This finding is different from previous findings (e.g., Costa et al., 2006; Pierce \& Newstrom, 1983). Used flexibility was negatively related to physical health, which again was different than the previous findings from other studies noted previously (e.g., Grzywacz et al., 2008). These findings may be unique to this multicultural sample from Singapore.

\section{Limitations}

This study has several limitations. First, it uses self-report, survey data only. It may be beneficial in future research to also include other types of data less subject to bias. Next, its data are cross-sectional. Because the model infers cause-and-effect relationships, a longitudinal design would better demonstrate causality. In addition, there are questions about the degree to which these data from Singapore may be generalized to other parts of the world. For this reason, future research is needed throughout other industrialized areas of the world. Researchers should focus on how the impact of flexibility is influenced by culture and work environments.

\section{Conclusions}

In numerous contexts research has demonstrated that workplace flexibility and work-family fit are directly and indirectly related to outcomes that are beneficial to individuals, families, and businesses. What this study contributes is that actually using workplace flexibility is not a prerequisite to achieve these outcomes. Indeed, just the perception that the flexibility would be available when needed appears to be sufficient. This means that businesses, nations, and policy makers who adopt flexible work options can realize that all individuals (and their families) may benefit, not just those who use the programs. 


\section{References}

Allen, T. D. (2001). Family supportive work environments: The role of organizational perceptions. Journal of Vocational Behavior, 58, 414-435.

Arbuckle, J. L. (2006). Amos 7.0 user's guide. Chicago: SPSS.

Aryee, S., Luk, V., \& Stone, R. (1998). Family-responsive variables and retention-relevant outcomes among employed parents. Human Relations, 5, 73-87.

Baltes, B. B., Briggs, T. E., Huff, J. W., Wright, J. A., \& Neuman, G. A. (1999). Flexible and compressed workweek schedules: A meta-analysis of their effects on work-related criteria. Journal of Applied Psychology, 84, 496-513.

Brennan, E. M., Rosenzweig, J. M., Ogilvie, A. M., Wuest, L., \& Shindo, A. A. (2007). Employed parents of children with mental health disorders: Achieving work-family fit, flexibility, and role quality. Families in Society, 88, 115-123.

Bromet, E. J., Dew, M. A., \& Parkinson, D. K. (1990). Spillover between work and family. In J. Eckenrode \& S. Gore (Eds.), Stress between work and family (pp. 131-151). New York: Plenum.

Byrne, B. M. (2001). Structural equation modeling with AMOS: Basic concepts, applications, and programming. Mahwah, NJ: Erlbaum.

Clark, S. C. (2000). Work/family border theory: A new theory of work/family balance. Human Relations, 53, 747-770.

Clarke, M. C., Koch, L. C., \& Hill, E. J. (2004). The work-family interface: Differentiating balance and fit. Family and Consumer Sciences Research Journal, 33, 121-140.

Costa, G., Sartori, S., \& Akerstedt, T. (2006). Influence of flexibility and variability of working hours on health and well-being. Chronobiology International, 23, 1125-1137.

Frone, M. R., \& Yardley, J. K. (1996). Workplace familysupportive programmes: Predictors of employed parents' importance ratings. Journal of Occupational and Organizational Psychology, 69, 351-366.

Galinsky, E., Bond, J. T., \& Hill, E. J. (2004). When work works: A status report on workplace flexibility. Who has it? Who wants it? What difference does it make? New York: Families and Work Institute.

Golden, T. D., Veiga, J. F., \& Simsek, Z. (2006). Telecommuting's differential impact on work-family conflict: Is there no place like home? Journal of Applied Psychology, 91, 1340-1350.

Grandey, A. A., Cordeiro, B. L., \& Crouter, A. C. (2005). A longitudinal and multi-source test of the work-family conflict and job satisfaction relationship. Journal of Occupational and Organizational Psychology, 78, 305-323.

Greenhaus, J. H., Allen, T. D., \& Spector, P. E. (2006). Health consequences of work-family conflict: The dark side of the workfamily interface. In P. L. Perrewe \& D. C. Ganster (Eds.), Research in occupational stress and well-being (Vol. 5). Amsterdam: Elsevier.

Greenhaus, J. H., \& Powell, G. N. (2006). When work and family are allies: A theory of work-family enrichment. Academy of Management Review, 31, 72-92.

Grzywacz, J. G., Almeida, D. M., \& McDonald, D. A. (2002). Work-family spillover and daily reports of work and family stress in the adult labor force. Family Relations, 51, 28-36.

Grzywacz, J. G., \& Bass, B. L. (2003). Work, family, and mental health: Testing different models of work-family fit. Journal of Marriage and Family, 65, 248-262.

Grzywacz, J. G., Carlson, D. S., \& Shulkin, S. (2008). Schedule flexibility and stress: Linking formal flexible arrangements and perceived flexibility to employee health. Community, Work, and Family, 11, 199-214.

Heymann, S. J., \& Earle, A. (2001). The impact of parental working conditions of school-age children: The case of evening work. Community, Work \& Family, 4, 305-326.

Hill, E. J. (2007). Singapore national study of work-life harmony: Final report. Provo, UT: Brigham Young University.

Hill, E. J., Ferris, M., \& Martinson, V. (2003). Does it matter where you work? A comparison of how three work venues (traditional office, virtual office, and home office) influence aspects of work and personal/family life. Journal of Vocational Behavior, 63, 220-241.

Hill, E. J., Grzywacz, J. G., Allen, S., Blanchard, V. L., MatzCosta, C., Shulkin, S., et al. (2008). Defining and conceptualizing workplace flexibility. Community, Work, \& Family, 11, 149-163.

Hill, E. J., Hawkins, A. J., Ferris, M., \& Weitzman, M. (2001). Finding an extra day a week: The positive influence of perceived job flexibility on work and family life balance. Family Relations, 50, 49-58.

Hill, E. J., Miller, B. C., Weiner, S. P., \& Colihan, J. (1998). Influences of the virtual office on aspects of work and work/life balance. Personnel Psychology, 51, 667-683.

Hoyle, R. H., \& Panter, A. T. (1995). Writing about structural equation models. In R. H. Hoyle (Ed.), Structural equation modeling: Concepts, issues, and applications (pp. 158-176). Thousand Oaks, CA: Sage.

Keene, J. R., \& Reynolds, J. R. (2005). The job costs of family demands: Gender differences in negative family-to-work spillover. Journal of Family Issues, 26, 275-299.

Kossek, E. E., Lautsch, B. A., \& Eaton, S. C. (2006). Telecommuting, control, and boundary management: Correlates of policy use and practice, job control, and work-family effectiveness Journal of Vocational Behavior, 68, 347-367.

Larson, R., Verma, S., \& Dworkin, J. (2001). Men's work and family lives in India: The daily organization of time and emotion. Journal of Family Psychology, 15, 206-224.

Macan, T. H. (1994). Time management: Test of a process model. Journal of Applied Psychology, 79, 381-391.

Morris, J. E., \& Coley, R. L. (2004). Maternal, family, and work correlates of role strain in low-income mothers. Journal of Family Psychology, 18, 424-432.

Netemeyer, R. G., Boles, J. S., \& McMurrian, R. (1996). Development and validation of work-family conflict and family-work conflict scales. Journal of Applied Psychology, 81, 400-410.

Perry-Jenkins, M., Repetti, R. L., \& Crouter, A. C. (2001). Work and family in the 1990s. In R. M. Milardo (Ed.), Understanding families into the new millennium: A decade in review (pp. 200-217). Minneapolis, MN: National Council on Family Relations.

Pierce, J. L., \& Newstrom, J. W. (1983). The design of flexible work schedules and employee responses: Relationships and process. Journal of Occupational Behavior, 4, 247-262.

Pittman, J. F. (1994). Work/family fit as a mediator of work factors on marital tension: Evidence from the interface of greedy institutions. Human Relations, 47, 183-209.

Repetti, R. L., \& Wood, J. (1997). Effects of daily stress at work on mothers' interactions with preschoolers. Journal of Family Psychology, 11, 90-108.

Reynolds, J., \& Aletraris, L. (2007). Work-family conflict, children, and hour mismatches in Australia. Journal of Family Issues, 28, 749-772.

Sanchez, A. M., Perez, M. P., de Luis Carnicer, P., \& Jimenez, M. J. V. (2007). Tele-working and workplace flexibility: A study of impact of firm performance. Personnel Review, 36, 42-64.

Sandholtz, K., Derr, B., Buckner, K., \& Carlson, D. (2002). Beyond juggling. Rebalancing your busy life. San Francisco: Berrett-Koehler.

Schultz, M. S., Cowan, P. A., Cowan, C. P., \& Brennan, R. T. (2004). Coming home upset: Gender, marital satisfaction, and the 
daily spillover of workday experience into couple interactions. Journal of Family Psychology, 18, 250-263.

SPSS. (2007). AMOS for Windows, rel. 7.0 [Computer software]. (2007). Chicago: Author.

Stevens, D. P., Kiger, G., \& Riley, P. J. (2006). His, hers, or ours? Work-to-family spillover, crossover, and family cohesion. The Social Science Journal, 43, 425-436.

Thornthwaite, L. (2004). Working time and work-family balance: A review of employees' preferences. Asia Pacific Journal of Human Resources, 42, 166-184.

U.S. Department of Labor. (1999). Futurework: Trends and challenges for work in the 21st century. Washington, DC: Author. Retrieved October, 27, 2007, from http://www.dol.gov/asp/ programs/history/herman/reports/futurework/report.htm
Van den Berg, P., \& Van der Velde, M. (2005). Relationships of functional flexibility with individual and work factors. Journal of Business and Psychology, 20, 111-129.

Voydanoff, P. (2005). Toward a conceptualization of perceived work-family fit and balance: A demands and resources approach. Journal of Marriage and Family, 76, 822-836.

Wang, P., \& Walumbwa, F. O. (2007). Family-friendly programs, organizational commitment, and work withdrawal: The moderating role of transformational leadership. Personnel Psychology, 60, 397-427.

Received January 17, 2008

Revision received June 19, 2008

Accepted June 23, 2008

\section{ORDER FORM}

\section{Start my 2009 subscription to the Journal of Family Psychology ISSN:0893-3200}

$$
\begin{array}{ll}
\$ 55.00 & \text { APA MEMBER /AFFILIATE } \\
\$ 149.00 & \text { INDIVIDUAL NONMEMBER } \\
\$ 435.00 & \text { INSTITUTION } \\
& \text { In DC add } 5.75 \% / \text { In MD add 6\% sales tax } \\
& \text { TOTAL AMOUNT DUE }
\end{array}
$$

Subscription orders must be prepaid. Subscriptions are on a calendar year basis only. Allow 4-6 weeks for delivery of the first issue. Call for international subscription rates.

SEND THIS ORDER FORM TO

American Psychological Association

Subscriptions

750 First Street, NE

Washington, DC 20002-4242

AMERICAN

PSYCHOLOGICA

ASSOCIATION

Call 800-374-2721 or 202-336-5600

Fax 202-336-5568 :TDD/TTY 202-336-6123

For subscription information,

e-mail:subscriptions@apa.org
Check enclosed (make payable to APA)

Charge my: $\square$ Visa $\square$ MasterCard $\square$ American Express

Cardholder Name

Card No. _ Exp. Date

Signature (Required for Charge)

\section{Billing Address}

Street

City State Zip

Daytime Phone

E-mail

Mail To

Name

Address

City State Zip 